\title{
Stigma related to mental health issues - a study among adolescents in Sri Lanka
}

UR Attygalle, H Perera, BDW Jayamanne

\section{Abstract \\ Introduction}

It is well known that stigma is a key contributory factor for delayed help seeking in mental health issues. This in turn has led to poor outcomes amongst those who suffer from mental health issues. In Sri Lanka, large studies on stigma amongst adolescents are limited.

\section{Aims}

This study aims to describe the attributes of stigma in relation to selected mental health issues amongst adolescents.

\section{Methods}

This is a descriptive cross-sectional study focusing on data collected from 1002 adolescents. The data was collected using a questionnaire based on the Children's Attribution Questionnaire (AQ-8-C). Case vignettes depicting depression with suicidal ideation, social phobia, psychosis and a physical health issue, namely diabetes, was used.

Results

The study revealed that the likelihood of providing help was significantly higher with regards to mental health issues compared to diabetes $(p<0.001)$, while the likelihood of avoiding a mental health patient was higher in psychosis compared to the other vignettes $(p<0.001)$.

Those with a personal or family history of mental health issues had a higher tendency of avoiding or being angered by such patients, or considering the person in the mental health vignette to be dangerous $(p<0.05)$.

\section{Conclusions}

Adolescents in this cohort stated they were more likely to help in the case of a person with a mental health issue, compared to someone with diabetes. They were more likely to stay away from those with psychosis, compared to those with other mental health issues. Exposure to mental health issues did not appear to lower the stigma associated with these disorders.

Key words: Adolescents, stigma, attitudes, mental health

SL J Psychiatry 2020; 11(1): 8-13

\section{Introduction}

One definition of stigma is that it is a "collection of negative attitudes, beliefs, thoughts, and behaviours that influence the individual or the general public to fear, reject, avoid, be prejudiced, and discriminate against people” (1). Stigma impedes treatment seeking, erodes self-esteem and limits the individual's social network. Although stigma was described as a unitary characteristic in earlier studies, currently it is understood as being more complex and having many dimensions and attributes (2-4). Culture also influences the way stigma relating to mental illness is presented (5).

One key step in the development of stigma in mental health issues is the perception of difference (6). Another aspect is the socially attributed stereotypes of violence and unpredictability in relation to mental health issues (6). These social stereotypes tend to place those with mental health issues in a different category to those without these issues, thereby exaggerating the difference between the two groups (7). In addition to impeding treatment seeking, it negatively impacts on social integration and employment opportunities for those with mental health issues $(8,9)$.

Adolescents with mental health issues report similar problems, including peer related issues and poor help seeking (10). Adolescence is also considered a key period in one's life, when most mental health issues begin to develop $(11,12)$. However, early help seeking, identification and intervention could lead to much improved 
outcomes (13). Thus, reducing stigma and promoting early help seeking is essential in improving treatment results.

Although stigma among adolescents has been studied amongst western populations, there are very few studies conducted amongst Asian populations (3, 14-16). According to the most recent population and housing census In Sri Lanka, adolescents (aged between 10-19 years, both male and female) account for approximately $16.2 \%$ of the population (17). While there are no major studies on this subject among adolescents, a study among undergraduates in early adulthood concluded that creating greater awareness about mental health issues improved help-seeking (18). Therefore, the objective of this study is to describe several attributes of stigma related to a selection of mental health issues amongst school going adolescents.

\section{Methods}

This cross-sectional study was conducted in the Sri Jayewardenepura educational zone in the Colombo District. Those in grades 9 and 10 were chosen for the study. The minimum sample size was calculated to be 844. Details of sample size calculation can be found in a previously published study (19). A multistage cluster sampling method was used as this education zone included several categories of schools, with different resource levels and different streams of study, and a total of 46 schools were selected for the study (19).

Questions to assess stigma related to mental health issues, were adapted from the Attribution QuestionnaireC-8 (AQ-C-8), with the author's permission (20). This version of the questionnaire has been formulated for children and applied on adolescents between $10-18$ years to assess for public stigma (20). The attribution questionnaire uses a collection of attributes about people with mental health issues (such as pity, shame, guilt, level of perceived danger, likelihood of helping or staying away from them). The selected attributes were self-scored by participants on a pre-coded 9 response Likert scale, with a higher score indicating that the given attributes were being more strongly endorsed by the respondent (i.e., score of 9-strongly agree and a score of 1 - strongly disagree).

The participants were asked to score these attributes in relation to four case vignettes. These vignettes were modelled on the Australian National Survey on Mental Health Literacy and Stigma 2011 (15). The four case vignettes used in the current study were: depression with suicidal ideation, social phobia, psychosis and diabetes mellitus. A vignette on a physical health condition (diabetes mellitus) was included for comparison. The content and face validity of the questionnaire was established using the Delphi method. A pilot study was also conducted to establish acceptance, comprehension and ease of administration (19). The data was analysed for frequency distribution, crosstabulation and median comparisons. A p value of 0.05 was used as the significance level.

\section{Ethics}

Consent and approvals have been obtained from the respective education offices of each zone and the principals of the selected schools. Ethical clearance for the study was obtained from the Ethics Review Committee (ERC) of the University of Colombo, Sri Lanka. The data collector visited the schools and obtained prior consent (informed and written) from the parents of students selected for the study. Information sheets about the study were also shared with the consent forms. Only those adolescents with parental consent were included in the study. Prior assent from participating adolescents was also obtained.

\section{Results}

Of the 1,500 students approached, 1,002 responded (response rate of 67\%). There were 590 (58\%) males in the sample with a mean age of 14 years ( $S D \pm 0.94)$. An average monthly family income of more than LKR 20,000 was seen among $59.4 \%$ of the sample. Of the sample, $9.6 \%(n=97)$ responded positively to knowing a relative with mental health issues (family history), while 5.2\% $(n=52)$ responded positively to being treated for a mental health issue themselves (personal history). The central tendencies (mean and median scores), for the different stigma related attributes are listed in Table 1.

A comparison of the median scores of each attribute between the different vignettes showed that there was a significant difference only for the attributes of blame, anger, willingness to help and preference to stay away $(p<0.05)$ (Table 2). The overall scores for anger and staying away were significantly higher $(p<0.05)$ for psychosis compared to depression or social phobia (Table 2).

Comparison of median values in relation to family income (categorised as below and above LKR 20,000), the education level of the mother and father (categorised as above and below the General Certificate in Education Ordinary Level exam) did not show significant difference in relation to any of the attributes.

A family history or a personal history of being treated for a mental health issue in the past, was associated with a significantly higher median score for the attributes of avoidance, anger, and danger across all three mental health vignettes $(\mathrm{p}<0.05)$ (Table 3$)$. A personal history was also significantly associated with lower median scores for pity and willingness to help $(\mathrm{p}<0.05)$ (Table 3). 
Table 1. Median and mean scores for the stigma related attributes (pity, dangerousness, blame, anger, help and staying away) between the 4 case vignettes

(Scores towards 1 indicate strong disagreement, and towards 9 indicate strong agreement)

\begin{tabular}{|c|c|c|c|c|c|c|}
\hline & \multicolumn{5}{|c|}{ Percentiles } \\
\hline & & Median & 25 & 75 & Mean & Std. Deviation \\
\hline \multirow{6}{*}{ 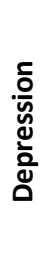 } & I would feel pity for him & 8.00 & 6.00 & 9.00 & 7.29 & 2.252 \\
\hline & I would feel that he is a dangerous & 2.00 & 1.00 & 3.00 & 2.43 & 2.253 \\
\hline & I would think he is to blame for his condition & 5.00 & 1.00 & 8.00 & 4.55 & 2.068 \\
\hline & I would feel angry towards him & 1.00 & 1.00 & 2.50 & 2.17 & 3.005 \\
\hline & I would think of helping him & 8.00 & 6.00 & 9.00 & 7.20 & 1.939 \\
\hline & I would think of staying away from him. & 1.00 & 1.00 & 3.00 & 2.22 & 2.489 \\
\hline \multirow{6}{*}{$\begin{array}{l}\frac{\pi}{0} \\
\frac{0}{0} \\
\frac{2}{0} \\
\frac{\pi}{0} \\
\frac{0}{0}\end{array}$} & I would feel pity for him & 8.00 & 6.00 & 9.00 & 7.16 & 1.988 \\
\hline & I would feel that he is a dangerous & 1.00 & 1.00 & 2.00 & 2.07 & 2.494 \\
\hline & I would think he is to blame for his condition & 5.00 & 2.00 & 8.00 & 4.82 & 1.896 \\
\hline & I would feel angry towards him & 1.00 & 1.00 & 3.00 & 2.23 & 3.086 \\
\hline & I would think of helping him & 8.00 & 7.00 & 9.00 & 7.32 & 2.013 \\
\hline & I would think of staying away from him. & 1.00 & 1.00 & 3.00 & 2.32 & 2.437 \\
\hline \multirow{6}{*}{ 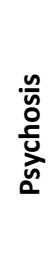 } & I would feel pity for him & 8.00 & 6.00 & 9.00 & 7.10 & 2.172 \\
\hline & I would feel that he is a dangerous & 2.00 & 1.00 & 4.00 & 2.89 & 2.621 \\
\hline & I would think he is to blame for his condition & 4.00 & 1.00 & 8.00 & 4.46 & 2.425 \\
\hline & I would feel angry towards him & 2.00 & 1.00 & 3.00 & 2.42 & 3.109 \\
\hline & I would think of helping him & 8.00 & 6.00 & 9.00 & 7.18 & 2.201 \\
\hline & I would think of staying away from him. & 2.00 & 1.00 & 3.00 & 2.60 & 2.570 \\
\hline \multirow{6}{*}{$\begin{array}{l}\tilde{y} \\
\stackrel{ \pm}{ \pm} \\
\stackrel{0}{0} \\
\stackrel{0}{0}\end{array}$} & I would feel pity for him & 8.00 & 6.00 & 9.00 & 7.20 & 2.346 \\
\hline & I would feel that he is a dangerous & 1.00 & 1.00 & 3.00 & 2.23 & 2.544 \\
\hline & I would think he is to blame for his condition & 5.00 & 1.00 & 8.00 & 4.71 & 2.014 \\
\hline & I would feel angry towards him & 1.00 & 1.00 & 3.00 & 2.33 & 3.122 \\
\hline & I would think of helping him & 8.00 & 5.00 & 9.00 & 6.93 & 2.157 \\
\hline & I would think of staying away from him. & 1.00 & 1.00 & 3.00 & 2.36 & 2.694 \\
\hline
\end{tabular}

Table 2. Comparison of $p$-values with regards to the pattern of response, for the selected attributes (blame, anger, helping and staying away), between the four case vignettes

\begin{tabular}{|l|l|l|l|c|}
\hline Comparisons between case vignettes & Blame & Anger & Helping & $\begin{array}{c}\text { Staying } \\
\text { Away }\end{array}$ \\
\hline Depression and Social phobia & $0.0055^{*}$ & 0.5814 & $0.0081^{*}$ & 0.1478 \\
Depression and Psychosis & 0.2536 & $0.0005^{*}$ & 0.3886 & $0.0000^{*}$ \\
Depression and Diabetes & 0.1786 & $0.0276^{*}$ & $0.0017^{*}$ & $0.0206^{*}$ \\
Social phobia and Psychosis & $0.0001^{*}$ & $0.0039^{*}$ & 0.1387 & $0.0000^{*}$ \\
Social phobia and Diabetes & 0.2476 & 0.1554 & $0.0000^{*}$ & 0.6512 \\
Psychosis and Diabetes & $0.0146^{*}$ & 0.1475 & $0.0000^{*}$ & $0.0003^{*}$ \\
\hline
\end{tabular}

*significant $p$ values $(<0.05)$ 
Table 3: Comparison of median values of the stigma questionnaire, with respect to sex, family and personal history of mental illness

\begin{tabular}{|c|c|c|c|c|c|}
\hline Stigma related & attributes & & Social & & \\
\hline Pity & Sex (Male/ Female) & 0.124 & 0.689 & 0.495 & 0.022 \\
\hline & Family history of mental illness & 0.065 & 0.153 & 0.72 & 0.39 \\
\hline & Personal history of mental illness & $<0.001$ & $<0.001$ & $<0.001$ & 0.002 \\
\hline Dangerousness & Sex (Male/ Female) & 0.51 & 0.188 & 0.268 & 0.739 \\
\hline & Family history of mental illness & 0.003 & $<0.001$ & 0.008 & $<0.001$ \\
\hline & Personal history of mental illness & $<0.001$ & $<0.001$ & $<0.001$ & 0.001 \\
\hline Blame & Sex (Male/ Female & 0.001 & $<0.001$ & $<0.001$ & $<0.001$ \\
\hline & Family history of mental illness & 0.774 & 0.752 & 0.587 & 0.433 \\
\hline & Personal history of mental illness & 0.108 & 0.542 & 0.383 & 0.354 \\
\hline Anger & Sex (Male/ Female) & 0.461 & 0.422 & 0.114 & 0.487 \\
\hline & Family history of mental illness & $<0.001$ & 0.001 & $<0.001$ & $<0.001$ \\
\hline & Personal history of mental illness & $<0.001$ & $<0.001$ & $<0.001$ & $<0.001$ \\
\hline Helping & Sex (Male/ Female) & $<0.001$ & 0.268 & 0.001 & $<0.001$ \\
\hline & Family history of mental illness & 0.082 & 0.032 & 0.06 & $<0.001$ \\
\hline & Personal history of mental illness & $<0.001$ & $<0.001$ & $<0.001$ & $<0.001$ \\
\hline Staying away & Sex (Male/ Female) & 0.837 & $<0.001$ & 0.363 & 0.263 \\
\hline & Family history of mental illness & 0.001 & 0.005 & 0.002 & $<0.001$ \\
\hline & Personal history of mental illness & 0.003 & $<0.001$ & $<0.001$ & 0.001 \\
\hline
\end{tabular}

\section{Discussion}

\section{Stigma in relation to the different case vignettes}

In relation to all mental health case vignettes, there were higher scores for pity and helping the affected person and lower scores for danger, anger, and avoidance of the person, compared to the diabetes health vignette. Overall, this indicated that mental health issues were perceived as requiring more help, compared to those with diabetes. Interestingly, the responses also indicated that those with mental health issues were more likely to be offered help than those with diabetes, which was a good sign in relation to mental health issues.

The responses indicate that this cohort is more likely to avoid those with psychosis than those with depression or social phobia. Although one would expect the attribution of danger to be associated with avoidance, this was not indicated in the current study. Previous studies have shown that those with psychotic disorders and/or substance misuse are more stigmatized compared to those with other mental health issues (21). In another study on stigma among adolescents, relative to depression, psychosis was associated with higher scores on the dimensions of 'dangerous/unpredictable' and 'social distance' (14). In the 2011 National Mental Health Literacy survey in Australia (youth component), perceptions of danger, unpredictability and a desire for social distance were generally higher for psychosis/ schizophrenia, than for other disorders (15). However, in the current study the scores indicate that there was also significantly more anger in relation to psychosis than other mental health vignettes. Therefore, it is possible that in this study the reported avoidance of those with psychosis may be more related to anger than danger.

\section{Stigma expressed by those who know a family member with illness, or with a personal history of mental health issues}

In the current study, knowing a relative with a mental health issue, or having a personal history of being treated for a mental health issue was associated with a significant 
increase in the scores for the attributes of anger, danger and avoidance across all three mental health case vignettes. A personal history of being treated for mental health was associated with significantly lower scores for pity and the likelihood of helping. Although previous evidence has reported that knowledge of mental health issues and exposure to them has been found to lower stigma, some research suggests that knowledge and contact may also increase certain attributes of stigma (7, 20). The findings of the current study appear to support this latter view. The findings of this study suggest that it may not be mere exposure to mental health patients that reduce stigma. Factors such as the length of exposure, nature of experience (positive or negative experience), perception of treatment (beneficial and acceptable), and whether they recovered from their condition successfully, may all be important factors influencing stigma. A previous study reported that stigma was lower for an individual who suffered from major depression and recovered successfully after treatment, compared to an individual who was not treated (22). In another study undergraduates with a history of mental health treatment were assigned as room-mates to those with no mental health history. The stigma in the latter group stigma towards the former often increased, highlighting that naturalistic contact alone, if not structured appropriately, might be more harmful than helpful (23).

Thus, it might be that in this study sample, those with family and personal history of mental health issues did not have positive experiences/ outcomes, which may have influenced the degree and nature of stigma they have towards those with mental health issues.

\section{Limitations}

The responses of the participants may not necessarily indicate how they would respond in reality. This has been described as an issue in vignette based studies (24). As some of the data was retrospective, recall bias as well as courtesy bias may have influenced the responses. It is also likely that there are more attributes and dimensions of stigma than the ones used in this study. As various studies have used multiple tools with different dimensions and attributes, comparisons between studies is also difficult.

\section{Conclusions}

The findings of this study suggest that adolescents in this cohort are more likely to feel pity and help in the cases of mental health issues, compared to the case of the given physical health issue. They were also more likely to avoid those with psychosis, than those with other mental health issues. Thus, interventions aimed at reducing stigma could make use of this sense of pity and tendency to help, to promote directing those with mental health issues towards appropriate services. However, strategies will also have to consider ways of changing perceptions about psychosis related disorders, as avoidance by peers may lead to poorer help seeking where early intervention is most needed.

As seen in other studies, knowledge and exposure does not automatically reduce stigma towards those with mental health issues. In contrast, this study showed that merely knowing a person with mental health issues or having been treated for mental health issues can have a negative effect on stigma related attributes. As such, stigma mitigating programs may have to include aspects that go beyond mere exposure to those with mental health issues. A positive experience of the acceptability and benefits of treatment helping in recovery might be aspects to consider.

\section{Acknowledgements}

We would like to acknowledge the help provided by Prof P V R Kumarasiri at the Department of Community Medicine, Faculty of Medicine, University of Peradeniya, Sri Lanka during various stages of the study. We would also like to acknowledge the assistance of all the Education Department officials who helped in conducting this study.

\section{Funding}

This study was funded through the research allowance provided to medical officers attached to the Ministry of Health.

\section{Conflicts of interest}

None declared

UR Attygalle, Colombo South Teaching Hospital Kalubowila, Sri Lanka

H Perera, Formally of the Department of Psychological Medicine, Faculty of Medicine, University of Colombo, Sri Lanka

BDW Jayamanne, Department of Public Health, Faculty of Medicine, University of Kelaniya, Sri Lanka

Corresponding author: UR Attygalle

Email: udenaa@gmail.com

http://orcid.org/0000-0002-8064-2817 


\section{References}

1. Gary FA. Stigma. Barrier to Mental Health Care Among Ethnic Minorities. Issues Ment Health Nurs 2005; 26 (10): 979-99.

2. Brian K. Ahmedani. Mental Health Stigma: Society, Individuals, and the Profession. J Soc Work Values Ethics 2011; 8(2): 41-416.

3. Corrigan PW, Markowitz FE, Watson AC. Structural Levels of Mental Illness Stigma and Discrimination. Schizophr Bull 2004; 30(3): 481-491.

4. Lally J, ó Conghaile, A, Quigley S, Bainbridge E, McDonald C. Stigma of mental illness and help-seeking intention in university students. The Psychiatrist 2013; 37(8): 253-60.

5. Matthias C, Angermeyer MC, Carta MG, Matschinger H, Millier A, Refai T, Schomerus G. Cultural differences in stigma surrounding schizophrenia: comparison between Central Europe and North Africa. The Br J Psychiatry 2016; 208(4): 389-97.

6. Smith M. Stigma. Advances in Psychiatric Treatment 2002;8(5): 317-323.

7 Byrne P. Stigma of mental illness and ways of diminishing it. Advances in Psychiatric Treatment 2000;6(1): 65-72.

8. Corrigan PW, Penn DL. Lessons from social psychology on discrediting psychiatric stigma. Am Psychol 1999; 54(9): 765-76.

9. Rüsch N, Angermeyer, MC, Corrigan, PW. Mental illness stigma: concepts, consequences, and initiatives to reduce stigma. Eur Psychiatry 2005; 20(8): 529-39.

10. Kranke, DA, Floersch, J, Kranke BO, Munson MR. A Qualitative Investigation of Self-Stigma Among Adolescents Taking Psychiatric Medication. Psychiatr Serv 2011; 62(8): 893-9.

11. Kessler RC, Berglund P, Demler O, Jin R, Merikangas KR, Walters EE. Lifetime Prevalence and Age-of-Onset Distributions of DSM-IV Disorders in the National Comorbidity Survey Replication. Arch Gen Psychiatry 2005; 62(6); 593-602.

12. Shanahan L, Copeland W, Jane Costello E, Angold, A. Specificity of putative psychosocial risk factors for psychiatric disorders in children and adolescents. J Child Psychol Psychiatry 2008;49(1): 34-42.

13. McGorry $P$, van Os J. Redeeming diagnosis in psychiatry: timing versus specificity. Lancet 2013; 381: 343-5.
14. Jorm, AF, Wright A. Influences on young people's stigmatising attitudes towards peers with mental disorders: national survey of young Australians and their parents. Br J Psychiatry 2008; 192(2): 144-9.

15. Revealy N, Jorm AF. National Survey of Mental Health Literacy and Stigma. University of Melbourne (2011). Available at: http://pmhg.unimelb.edu.au/research_ settings/general_community?a=636496

16. Pang S, Liu J, Mahesh M, Chua BY, Shahwan S, Lee SP, Vaingankar JA, Abdin E, Fung DSS, Chong SA, et al. Stigma among Singaporean youth: a cross-sectional study on adolescent attitudes towards serious mental illness and social tolerance in a multiethnic population. BMJ Open. 2017; 7(10): e016432-e016432.

17. Department of Census and Statistics. Sri Lanka Population and housing census 2012. Colombo: Department of Census and Statistics; 2012. Available at :http://www. statistics.gov.lk/PopHouSat/CPH2011/Pages/Activities/ Reports/FinalReport/FinalReport.pdf

18. Amarasuriya DS, Jorm AF, Reavley JN. Depression literacy of undergraduates in a non-western developing context: the case of Sri Lanka. BMC Res Notes 2015; 8: 593.

19. Attygalle UR, Perera H, Jayamanne B. Mental health literacy in adolescents: ability to recognise problems, helpful interventions and outcomes. Child and adolescent psychiatry and mental health. J Child Psychol Psychiatry 2017; 11(38).

20. Corrigan PA, TOOLKIT for Evaluating Programs Meant to Erase the Stigma of Mental Illness. Chicago: Illinois Institute of Technology; 2012. Available at: http:// www.scattergoodfoundation.org/sites/default/files/ Evaluation\%20Toolkit_Corrigan.pdf

21. Corrigan PW, Lurie BD, Goldman HH, Slopen,N, Medasani, K, Phelan S. How Adolescents Perceive the Stigma of Mental Illness and Alcohol Abuse. Psychiatr Serv 2005; 56(5): 544-550.

22. Romer D. Bock M. Reducing the Stigma of Mental Illness Among Adolescents and Young Adults: The Effects of Treatment Information. J Health Commun 2008; 13(8): 742-58.

23. Eisenberg D, Golberstein E, Gollust, SE. Help-seeking and Access to Mental Health Care in a University Student Population. Med Care 2007; 45(7): 594-601.

24. Finch J. The Vignette Technique in Survey Research. Sociology 1987; 21(1): 105-14. 